\title{
On If-Then Multi Soft Sets-Based Decision Making
}

\author{
R.B. Fajriya Hakim ${ }^{1}$, Eka Novita Sari ${ }^{2}$, and Tutut Herawan ${ }^{3}$ \\ ${ }^{1}$ Department of Statistics \\ Universitas Islam Indonesia \\ Jalan Kaliurang KM 14, Yogyakarta Indonesia \\ ${ }^{2}$ AMCS Research Center \\ Yogyakarta, Indonesia \\ ${ }^{3}$ Department of Information System \\ University of Malaya \\ 50603 Pantai Valley, Kuala Lumpur, Malaysia \\ hakimf@fmipa.uii.ac.id, eka@amcs.co, tutut@um.edu.my
}

\begin{abstract}
Soft set theory as a new mathematical tool for dealing with uncertainties was first introduced by Molodtsov has experienced rapid growth. Various applications of soft set for the purpose of decision-making have been shown by several researchers. From various studies presented mostly shows the role of soft sets as a tool in the collection of the various attributes needed by a person to determine which decisions will be taken. In this paper, we show how soft set can play a role in the decision made by a person based on a history of decisions that have been made earlier and used as a reference for the next decision. Therefore, we introduce an (if-then) multi soft sets as a developments of application of soft set which is stated in the form if (antecedent) and then (consequence). The antecedent and consequence are derived from previously several decisions that have been made by people when using a soft set as a tool to help them for making a decision.
\end{abstract}

Keywords: Soft Set, Multi Soft Set, If-then, Decision making.

\section{Introduction}

Choosing one product to be purchased could be started by describing the product they want using some simple characteristics, attributes, information or knowledge they have about those product. Any parameters which had been regarded as an important characteristic that might be owned by the product to be bought could be collected in the structure of mathematical notion. Collection of those parameters can be laid on the form of soft set theory. Soft set theory first introduced by Molodtsov [1] in 1999 and has been applied in many fields by researchers. Hakim et al. [2] had proposed a recommendation analysis as a buyer tool to assist their decision in purchasing a product. Many researchers including Chen et al. [3], Feng et al. [4,5], Herawan and Mat Deris [6], Jiang et al. [7], Kong et al. [8], Maji et al. [9,10], Roy and Maji [11] mostly show the role of soft sets as a tool in the collection of various attributes or parameters of objects needed by a person and then determine using some calculations which decisions will be taken. The development of the use of soft set may actually be 
more than that, this paper will show how soft set can play a role in the decision made by a person based on a history of decisions that have been made by some people earlier and used as a reference for the next decision.

Deciding a product to be purchased is a difficult matter for a buyer. Hakim et al. [2] has introduced a recommendation system based on soft set theory to purchase a product from buyer side. This recommendation analysis is an advantage for buyers in helping them to determine the product they need. This paper also trying to use a soft set theory from a view of store team to observe the personality of buyer by means of the ability of the store owner and store assistant to evaluate their buyer when purchase goods. As a continuation of previous work, in this paper we develop an alternative application of soft set in the form if (antecedent) then (consequence) with antecedent as a condition attribute and consequence as a decision attribute that are derived from previously several decisions which had been made by other buyers. Because it involves a condition and decision attribute, we need a language of 'decision rules'. A decision rule is an implication in the form if $\mathrm{A}$ then $\mathrm{B}$, where $\mathrm{A}$ is called the 'condition' and B the 'decision' of the rule. Decision rules state relationship between conditions and decisions. In this paper, we are trying to combine the decision rules and dual soft sets that will produce a new application of soft set which can be known as if-then multi soft-set. This application not only helping buyer in deciding the product to be chosen, but also help the store to map their buyer when determining the product needed.

The rest of this paper is organized as follow. Section 2 describes rudimentary of soft set theory and soft solution for soft set. Section 3 describes the proposed application of if-then multi soft sets. Finally, the conclusion of this work is described in Section 4.

\section{Soft Set Theory and Soft Solution}

\subsection{Soft Set Theory}

Molodtsov [1] first defined a soft set which is a family of objects whose definitions depend on a set of parameter. Let $U$ be an initial universe of objects, $E$ be the set of adequate parameters in relation to objects in $U$. Adequate parameterization is desired to avoid some difficulties when using probability theory, fuzzy sets theory and interval mathematics which are in common used as mathematical tool for dealing with uncertainties. The definition of soft set is given as follows.

Definition 1. (See [1]). A pair $(F, E)$ is called a soft set over $U$ if and only if $F$ is a mapping of $E$ into the set of all subsets of the set $U$.

From definition 1 , a soft set $(F, E)$ over the universe $U$ is a parameterized family that gives an approximate description of the objects in $U$. Let $e$ any parameter in $E, e \in E$, the subset $F(e) \subseteq U$ may be considered as the set of $e$-approximate elements in the soft set $(F, E)$.

Example 1. Let us consider a soft set (F, E) which describes the "attractiveness of houses" that $\mathrm{Mr}$. $\mathrm{X}$ is considering to purchase. 


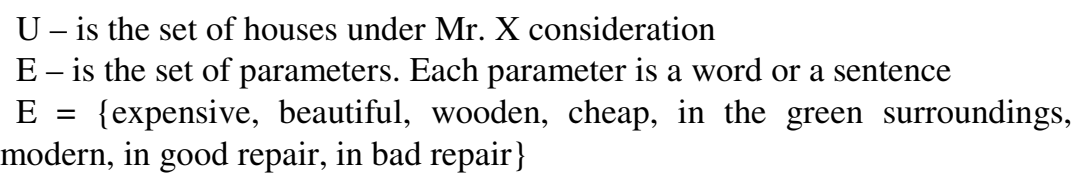

In this example, to define a soft set means to point out expensive houses, that shows which houses are expensive due to the dominating parameter is 'expensive' compared to other parameters that are possessed by the house, in the green surrounding houses, which shows houses that their surrounding are greener than other, and so on.

\subsection{Soft Solution of Soft Set Theory}

Many researches on soft set in decision making could be grouped into two groups. First, researchers that treat the soft set as an attribute of information system including the works of Herawan and Mat Deris [6], Zou and Xiao [12]) then using Rough Set to handle the vagueness for making a decision [5]. Second, researchers that use fuzzy theory to soft set including the works of Jun et al. [13], Feng et al. [4] and Jiang et al. [7]. Both of them gave techniques which produce best decision based on binary or fuzzy number rather than recommendation that may be little bit more satisfying Molodtsov's soft set philosophy. From the entire study could be seen that the whole objects under consideration was assessed through the parameters by the decision makers and will get the solution in the form of a subset of the objects itself that each of them has a dominating parameters. According to this understanding we will give the definition for soft solution of soft sets.

From that Definition 1, a soft set $(F, E)$ over the universe $U$ is a parameterized family that gives an approximate description of the objects in $U$. Let $e$ any parameter in $E, e \in E$, the subset $F(e) \subseteq U$ may be considered as the set of $e$-approximate elements in the soft set $(F, E)$. It is worth noting that the sets $F(e)$ may be arbitrary. Some of them may be empty, some may have nonempty intersection. That is, the solution of the soft set is a set which are a subset of object and a subset of parameters that shows the objects and its parameters.

Definition 2. (soft solution). A pair $\left(F^{\prime}, E^{\prime}\right)$ over $U^{\prime}$ is said to be a soft solution of soft $\operatorname{set}(F, E)$ over $U$ if and only if

i) $U^{\prime} \subseteq U$

ii) $\quad\left\{e_{\mid U^{\prime}}, e \in E\right\}=E^{\prime}$ where $e_{\mid U^{\prime}}$, is the restriction parameter of e to $U^{\prime}$

iii) $F$ ' is a mapping of $E^{\prime}$ into the set of all subsets of the set $U^{\prime}$

We shall use the notion of restriction parameter of $e \in E^{\prime}$ to $U^{\prime}$ in order to obtain the parameters which dominate an object compared to other parameters that may be possessed by those objects.

A soft set $(F, E)$ over $U$ might be considered as an information system $(U, A T)$ (Demri and Orlowska [14]) such that $A T=\{F\}$ and value of a mapping function of $F$ $=e \in E$ make available the same information about objects from $U$. It is a common thing to identify a wide range of matters (parameters) relating to the object and then create a collection of objects that possess this parameters. To compose this intuition, for a given soft set $S=(F, E)$ over $U$, we define a soft set formal context $S=(U, E, F)$ 
where $U$ and $E$ are non-empty sets whose elements are interpreted as objects and parameters (features), respectively, and $F \subseteq U \times E$ is a binary relation. If $x \in U$ and $e$ $\in E$ and $(x, e) \in F$, then the object $x$ is said to have the feature $e$. In this concept, the soft set formal context provides the following mappings ext: $\mathbf{P}(E) \rightarrow \mathbf{P}(U)$, that shows extensional information for objects under consideration. This means an object parameters may be able to be expanded on someone views as the set of those objects that possess the parameters.

Definition 3. For all $X \subseteq U$ and $e \subseteq E$ we define ext $(E) \stackrel{\text { def }}{\Rightarrow}\{x \in U \mid(x, e) \in F$, for every $e \in E\} ; \operatorname{ext}(E)$ is referred to as the extent of $E$.

A soft set formal context $S=(U, E, F)$ is an urn for a collection of soft sets. Not necessarily soft set formal context will only give one soft set. $S=(U . E, F)$ could be viewed as multi soft set, say dual soft set $S_{1}$ and $S_{2}$ where $S_{1}, S_{2} \subseteq S$ and $S_{1}$ is soft set $\left(F_{1}\right.$, $\left.E_{1}\right)$ over $U_{1}, S_{2}$ soft set $\left(F_{2}, E_{2}\right)$ over $U_{2}$, and $U_{1}, U_{2} \subseteq U$ and $E_{1}, E_{2} \subseteq E$ and $E_{1} \cap E_{2}=\varnothing$

Lemma 1. For Soft set formal context $S=(U . E, F), S_{1}, S_{2} \subseteq S$ and $S_{1}$ is soft set $\left(F_{1}\right.$, $\left.E_{1}\right)$ over $U_{1}, S_{2}$ soft set $\left(F_{2}, E_{2}\right)$ over $U_{2}$, for all $U_{1}, U_{2} \subseteq U$ and $E_{1}, E_{2} \subseteq E$ if $E_{1} \cap E_{2}$ $=\varnothing$, then $\operatorname{ext}\left(E_{1}\right) \cap \operatorname{ext}\left(E_{2}\right)=\varnothing$

Lemma above shows that a soft formal context can be divided into a number of soft sets (multi soft sets) with each object and its parameters are different but still in the same context. It is different from the multi soft sets proposed by Herawan and Mat Deris [15] who break the soft set but with the same object and parameters.

\section{The Proposed Application of If-Then Multi Soft Sets}

In this paper we will develop again the examples given by Hakim et al. [2] which illustrate a user interface of soft set recommendation analysis for purchasing furniture products in some furniture store. System (See Figure 1) displays three columns, first columns consists of customer identification and buyers are offered to get assistant from furniture expert for choosing and question of some specific purpose in intending buying the furniture. All collections of furniture items are shown in second column and buyer was asked to choose one of collections. In this example, buyers choose dining chairs then the third column display all collection of dining chairs. Four selected chairs as depicted in Figure 2 are chosen by customer and buyers could determine their own requirements for their dining chairs. Buyer has several things that he thought as a dining chairs precondition, he could type any perspective inside the form, for example, 'match with my dining room decoration', 'fit the space of my dining room', 'cheap', 'comfort', 'classic' and 'wood color'. This could be expressed in the form of soft set. A soft set $\left(F_{1}, E_{1}\right)$ of this example could be described as the preconditions of the chairs which buyer is going to buy.

$U_{1}$ - is the set of chairs under consideration $\{\mathrm{Ch} 1, \mathrm{Ch} 2, \mathrm{Ch} 3, \mathrm{Ch} 4\}$

$E_{1}-$ is the set of parameters. Each parameter is a word or a sentence.

$E_{1}=\{$ match with my dining room decoration, fit the space of my dining room, cheap, comfort, classic and wood color 
Those preconditions could be regarded as parameters of each chair. He thought that, those information/ knowledge/parameters are necessary parameters for him to choose a chair that he need for inviting a special guest for dinner. Soft set has applied here, that someone could use any parameterization he wants for purchasing chairs. It might he only knows what he need and conditions that he must consider putting the chairs then. Meanwhile, in this cases we offer a judgment from expert based on buyer's precondition which is available in the form below the 'customer request', this form shows what Expert Says with the valuation of each chair below of its pictures. In the second column, it also displays the form of customer evaluation that he could determine his own judgment for each chair. The simple act to evaluate the selected items is to compare them in a fairly flexible way by giving a mark to the chairs that meet his requirements. More asterisks more meet parameters. After giving an assessment of the selected chairs, the last column gives the soft solution. The soft solution of soft set for this problem is

Soft solution $\left(F_{1}{ }^{\prime}, E_{1}{ }^{\prime}\right)=\{($ Match the dining room decoration $)=$ Ch1,$($ Wood color, Comfort, Classic) $=\mathrm{Ch} 2$, (Fit the space of dining room, Cheap, Match the dining room decoration) = $\mathrm{Ch} 3,($ Cheap $)=\mathrm{Ch} 4\}$

This set of soft solution is used as a recommendation for buyer to purchase the chairs. This soft solution is a result of soft set using hierarchical clustering and multidimensional scaling techniques. Outcome of this solution is a recommendation based on buyer's evaluation, for example, the first picture show that the chair tends to match with the dining room decoration while second picture meet a lot of customer requests, i.e., wood color, comfort and classic style. The final decision is verified by customer to buy that chair. The last row could be utilized as an offer to buyer for buying another product which is usually bought by others while buying that chair.

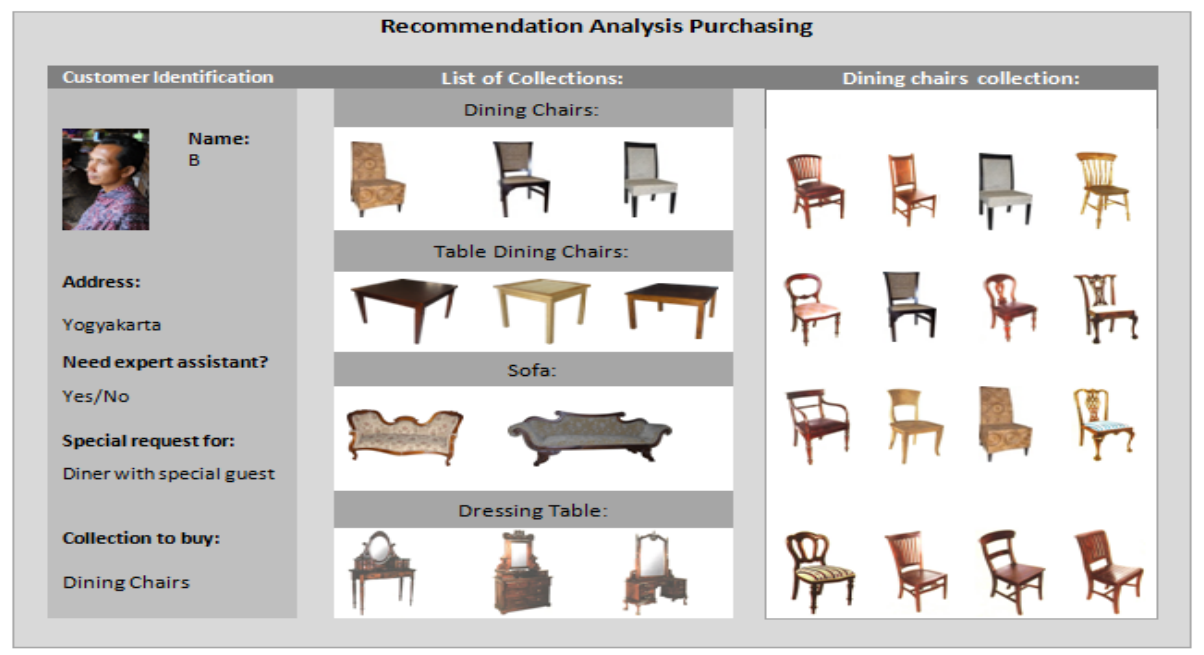

Fig. 1. Soft set recommendation analysis on first page 


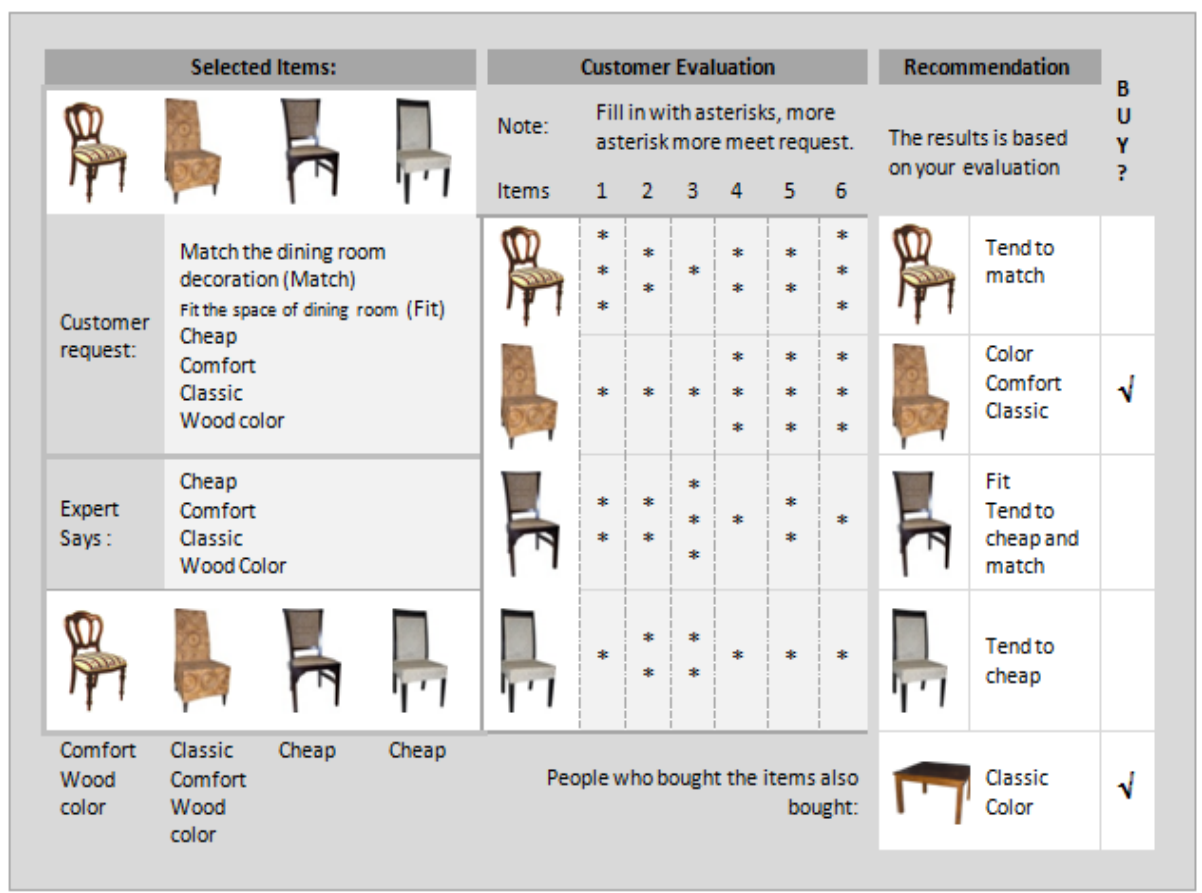

Fig. 2. Soft set recommendation analysis on second page

Nowadays buyers are miserly to give personal information due to security reason and get annoyed when shop assistant started asking personal things. Shop assistant also cannot force the buyers ask for personal information, but much better if observing the behavior of buyers when selecting products and make their choice. Simple research will be carried out if the shop owner does not assume the arrival of buyer to their shop only as a destiny. Buyer that has already coming to their shops should be noticed use any kind of characteristics or parameters which the owner or shop assistant could do. Some simple parameters that might could be used to differentiating one person to another such as, appearance of buyers, style of buyers when asking something, gesture of buyers, speaking style of buyer and so on.

In this example, the furniture store owner and their team trying to observe their buyer using several parameter which could be put in the form of set \{tidy appearance, looks wealthy, age-old, too much questions, modern lifestyle, complicated requests, busy and in hurry, too much bargain \} that they think sufficient to evaluate their buyer. Other owners could add or reduce the parameter used in this set, depend on the observation to their own buyers. A soft set $\left(F_{2}, E_{2}\right)$ of this example could be described as the behavior of buyers as the result of observation of the owner

$U_{2}$ - is the set of buyers under consideration $\{\mathrm{A}, \mathrm{B}, \mathrm{C}, \mathrm{D}\}$

$E_{2}-$ is the set of parameters. Each parameter is a word or a sentence.

$E_{2}=\{\{$ tidy appearance, looks wealthy, age-old, too much questions, modern lifestyle, complicated requests, busy and in hurry, too much bargain \}. 
The owners could ask his/her employee to help him in judging their buyers. Of course, the owner and other employee do not need to become an expert in advance at the field of human personality evaluation. They just give simple evaluation in accordance to their ability to observe and what they feel about their buyer. In this example suppose the owner choose 4 buyers that had been made a transaction with him. Those buyer will be evaluated based on observation in which the owner and its team remembering again behavior of the buyer when they was in their store. The way of dealing with evaluation usually using ranking or rating to the objects under consideration and express their perception in an easiest and fairly flexible way. The simplest expression is give ranking by using an asterisk that show more asterisk in the parameter means more adjacent the parameter belonging to the object. The owner will give more asterisks if one buyer meets the parameters than other buyer. For instance, in parameter 'tidy appearance' Mr. B seems the most tidy than others. Mr. C seems as tidy as Mr. D, even though both of them not really equal tidy in appearance. Mr. A is the most not tidy compared to other three buyers. Mr. C looks the wealthiest than others, Mr. A and Mr. D looks same wealthy and Mr. B looks not so wealthy. Evaluation could be continued to the next parameters. Tabular representation of the buyers and parameters would be useful to describe the response of shop owner and his team in evaluating their buyers (Refer to Table 1).

Table 1. Evaluation of shop owner to his/her buyers

\begin{tabular}{|c|c|c|c|c|c|c|c|c|}
\hline & $\begin{array}{c}\text { Tidy } \\
\text { appearance }\end{array}$ & $\begin{array}{c}\text { Looks } \\
\text { wealthy }\end{array}$ & $\begin{array}{c}\text { Age- } \\
\text { old }\end{array}$ & $\begin{array}{c}\text { Too } \\
\text { much } \\
\text { question }\end{array}$ & $\begin{array}{c}\text { Modern } \\
\text { lifestyle }\end{array}$ & $\begin{array}{c}\text { Complicated } \\
\text { requests }\end{array}$ & $\begin{array}{c}\text { Busy } \\
\text { and in } \\
\text { hurry }\end{array}$ & $\begin{array}{c}\text { Too } \\
\text { much } \\
\text { bargain }\end{array}$ \\
\hline $\mathrm{A}$ & $*$ & $* *$ & $* * *$ & $* *$ & $*$ & $* *$ & $*$ & $* *$ \\
\hline $\mathrm{B}$ & $* * *$ & $*$ & $* * *$ & $* * *$ & $*$ & $* * *$ & $*$ & $* * *$ \\
\hline $\mathrm{C}$ & $* *$ & $* * *$ & $* *$ & $*$ & $* * *$ & $*$ & $* * *$ & $* *$ \\
\hline $\mathrm{D}$ & $* *$ & $* *$ & $*$ & $* * *$ & $* * *$ & $*$ & $* *$ & $*$ \\
\hline
\end{tabular}

To better utilizing information from the tables and providing added value for the shop owner, the multidimensional scaling techniques will be used. Non-metrix multidimensional scaling techniques are common techniques which based on ordinal or qualitative rankings of similarities data [16]. Therefore, Table 1 needs to be transformed via the numbers into an ordinal table (Refer to Table 2).

Table 2. Ordinal numbers of Table 1

\begin{tabular}{|c|c|c|c|c|c|c|c|c|}
\hline & $\begin{array}{c}\text { Tidy } \\
\text { appearance }\end{array}$ & $\begin{array}{c}\text { Looks } \\
\text { wealthy }\end{array}$ & $\begin{array}{c}\text { Age- } \\
\text { old }\end{array}$ & $\begin{array}{c}\text { Too } \\
\text { much } \\
\text { question }\end{array}$ & $\begin{array}{c}\text { Modern } \\
\text { lifestyle }\end{array}$ & $\begin{array}{c}\text { Complicated } \\
\text { requests }\end{array}$ & $\begin{array}{c}\text { Busy } \\
\text { and in } \\
\text { hurry }\end{array}$ & $\begin{array}{c}\text { Too } \\
\text { much } \\
\text { bargain }\end{array}$ \\
\hline A & 1 & 2 & 3 & 2 & 1 & 2 & 1 & 2 \\
\hline B & 3 & 1 & 3 & 3 & 1 & 3 & 1 & 3 \\
\hline C & 2 & 3 & 2 & 1 & 3 & 1 & 3 & 2 \\
\hline D & 2 & 2 & 1 & 3 & 3 & 1 & 2 & 1 \\
\hline
\end{tabular}

Using the software R (R Development Core Team [17]) with vegan package and metaMDS procedure (Dixon and Palmer [18]), we get the mapping of buyers and its parameters as depicted in Figure 3. 


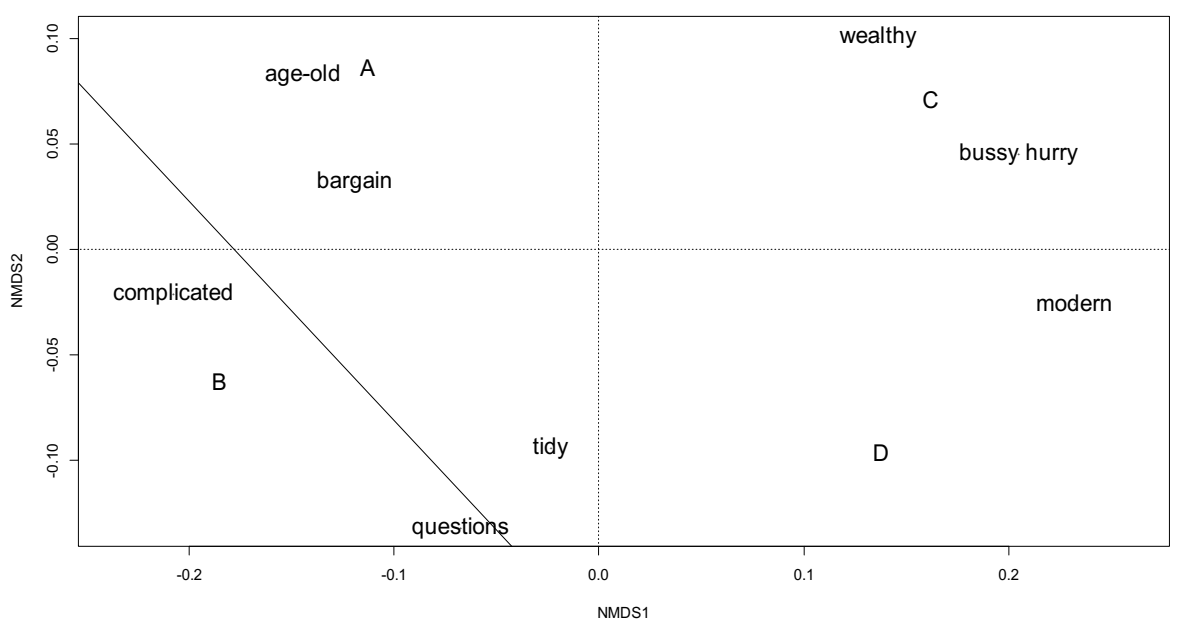

Fig. 3. Multidimensional scaling plot of buyers and its parameters

And the soft solution of soft set for the behavior of buyers is

$$
\begin{aligned}
\text { Soft solution }\left(F_{2}, E_{2}{ }^{\prime}\right)= & \{(\text { Age-old, Too much bargain })=\mathrm{A}, \\
& (\text { Tidy appearance, Too much questions, } \\
\text { Complicated requests })=\mathrm{B}, & \\
& (\text { Wealthy, Busy and hurry })=\mathrm{C}, \\
& (\text { Modern lifestyle })=\mathrm{D}\}
\end{aligned}
$$

From this two soft set $\left(F_{1}, E_{1}\right)$ and $\left(F_{2}, E_{2}\right)$ give a result of two soft solution which are $\left(F_{1}, E_{1}{ }^{\prime}\right)$ and $\left(F_{2}, E_{2}{ }^{\prime}\right)$ and due to high relationship between two soft set, the owner could get the decision rules of two soft solution which are

$$
\text { If }\left(F_{1}{ }^{\prime}, E_{1}{ }^{\prime}\right) \text { then }\left(F_{2}{ }^{\prime}, E_{2}{ }^{\prime}\right) \text { or } \quad \text { if }\left(F_{2}, E_{2}{ }^{\prime}\right) \text { then }\left(F_{1}{ }^{\prime}, E_{1}{ }^{\prime}\right)
$$

Say, the owner would like to take one of those buyer to see the decision rules of multi soft set, say Mr. B, then he will get the rules,

if $\left|\begin{array}{l|l}\text { Mr. B bought chair } \\ \begin{array}{l}\text { Classic, Comfort, } \\ \text { Wood color }\}=(\mathrm{Ch} 2)\end{array} \mid\end{array}\right|$ then $\mid \begin{aligned} & \text { Mr. B is \{Tidy appearance, } \\ & \text { Too much questions, } \\ & \text { Complicated requests }\}\end{aligned}$

or

$$
\text { If }\left|\begin{array}{l}
\text { Mr. B } \quad \text { is } \quad \text { Tidy } \\
\begin{array}{l}
\text { appearance, Too much } \\
\text { questions, Complicated } \\
\text { requests }\}
\end{array}
\end{array}\right| \text { then } \mid \begin{aligned}
& \text { Mr. B bought chair } \\
& \{\text { Classic, Comfort, Wood } \\
& \text { color }\}=(\text { Ch2 })
\end{aligned}
$$

Second rule seems reasonable for recommendation which will be used by the owner and his sales person to a buyer who have behavior looks like Mr. B. Of course this rule will not be disclosed to the buyer, because the rules are based on the assessment of shopkeeper to their buyers quietly. Even though this recommendation is 


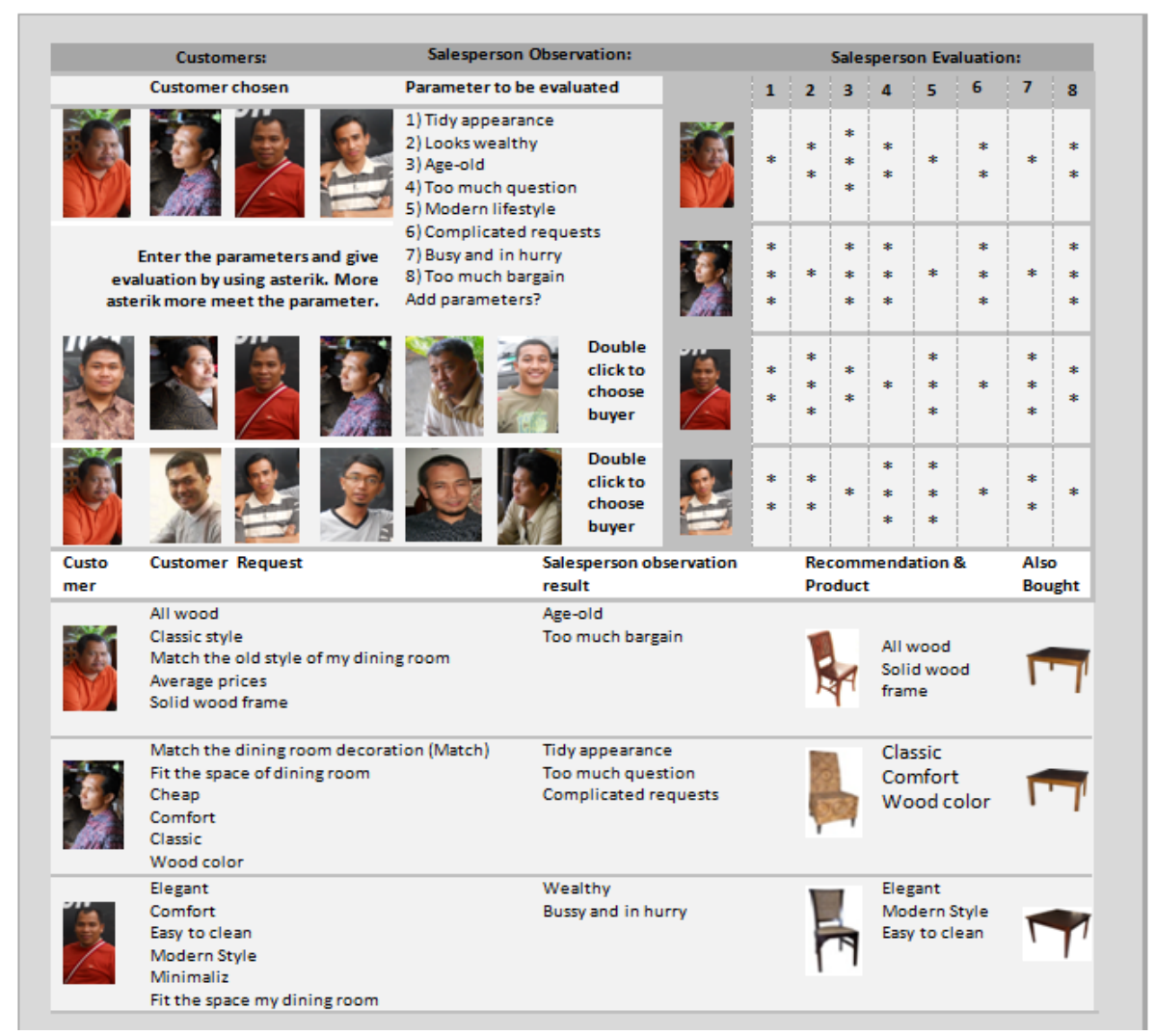

Fig. 4. Interface of application if-then multi soft set

not exact decision but this rules could help the owner and the sales person to assist the buyers while they are determining to choose one chair from several chairs of dining room. Figure 4 shows the interface of recommendation analysis of the owner to their buyers. This work has already shown the applied of soft set when it is implemented in the rules if-then. The usage of multi soft set, could help not only buyer when he/she need to choose the object he wants but also help the shop owner to give recommendation to his/her buyer based on buyer behavior.

\section{Conclusion}

Soft set theory which is a new mathematical tool in decision making already gave lack of restrictions to one whom using them in achieving the final decision. Anyone could use any parameters in deciding which objects will be chosen. From many previous studies mostly shows the role of soft sets as a tool in the collection of the various parameters needed by a person to determine which decisions will be taken, however in this paper we have already shown the development of the use of soft set to multi soft sets and its lemma. We have shown how if-then multi soft set can play a role in the decision made by a person based on a history of decisions that have been made by some people earlier and used as a reference for the next decision. 
Acknowledgments. This work is supported by University of Malaya High Impact Research Grant no vote UM.C/625/HIR/MOHE/SC/13/2 from Ministry of Higher Education Malaysia.

\section{References}

1. Molodtsov, D.: Soft Set Theory - First Results. Computers and Mathematics with Applications 37, 19-31 (1999)

2. Hakim, R.B.F., Subanar, Winarko, E.: Recommendation Analysis Based on Soft Set for Purchasing Products. In: Proceedings of the 6th Southeast Asian Mathematical Society (SEAMS) International Conference of Mathematics and Its Application, pp. 831-848 (2011)

3. Chen, D., Tsang, E.C.C., Yeung, D.S., Wang, X.: The Parameterization Reduction of Soft Sets and its Applications. Computers and Mathematics with Applications 49, 757-763 (2005)

4. Feng, F., Jun, Y.B., Liu, X., Li, L.: An adjustable approach to fuzzy soft set based decision making. Journal of Computational and Applied Mathematics 234, 10-20 (2010)

5. Feng, F., Liu, X., Leoreanu-Fotea, V., Jun, Y.B.: Soft set and soft rough sets. Information Sciences 181, 1125-1137 (2011)

6. Herawan, T., Mat Deris, M.: A soft set approach for association rules mining. Knowledge Based System 24, 186-195 (2011)

7. Jiang, Y., Tang, Y., Chen, Q.: An adjustable approach to intuitionistic fuzzy soft sets based decision making. Applied Mathematical Modeling 35, 824-836 (2011)

8. Kong, Z., Gao, L., Wang, L., Li, S.: The normal parameter reduction of soft sets and its algorithm. Comput. Math. Appl. 56, 3029-3037 (2008)

9. Maji, P.K., Roy, A.R., Biswas, R.: An Application of Soft Sets in A Decision Making Problem. Computers and Mathematics with Applications 44, 1077-1083 (2002)

10. Maji, P.K., Roy, A.R., Biswas, R.: Soft Sets Theory. Computers and Mathematics with Applications 45, 555-562 (2003)

11. Roy, A.R., Maji, P.K.: A Fuzzy Soft Set Theoretic Approach to Decision Making Problems. Computational and Applied Mathematics 203, 412-418 (2007)

12. Zou, Y., Xiao, Z.: Data Analysis Approaches of Soft Sets under Incomplete Information. Knowledge Based System 21, 941-945 (2008)

13. Jun, Y.B., Lee, K.J., Park, C.H.: Fuzzy soft sets theory applied to BCK/BCI-algebras. Computers and Mathematics with Applications 59, 3180-3192 (2010)

14. Demri, S.P., Orlowska, E.S.: Incomplete Information: Structure, Inference, Complexity. Springer, Heidelberg (2002)

15. Herawan, T., Mat Deris, M.: On multi soft sets construction in information systems. In: Huang, D.-S., Jo, K.-H., Lee, H.-H., Kang, H.-J., Bevilacqua, V. (eds.) ICIC 2009. LNCS (LNAI), vol. 5755, pp. 101-110. Springer, Heidelberg (2009)

16. Kruskal, J.B.: Nonmetric multidimensional scaling: A numerical method. Psychometrika 29, 115-129 (1964)

17. R Development Core Team: R: A language and environment for statistical computing, $R$ Foundation for Statistical Computing, Vienna, Austria (2006)

18. Dixon, P., Palmer, M.W.: Vegan, a package of R function for community ecology. Journal of Vegetation Science 14, 927-930 (2003) 